\title{
TECHNOLOGIES AND STRATEGIES TO DESIGN SUSTAINABLE TOURIST ACCOMMODATIONS IN AREAS OF HIGH ENVIRONMENTAL VALUE NOT CONNECTED TO THE ELECTRICITY GRID
}

\author{
F. CUMO ${ }^{1}$, D. ASTIASO GARCIA ${ }^{2}$, V. STEFANINI ${ }^{3} \&$ M. TIBERI ${ }^{2}$ \\ ${ }^{1}$ CITERA (Interdisciplinary Centre for Housing, Heritage and Environment), Sapienza University of Rome, Italy. \\ ${ }^{2}$ Department of Astronautical, Electrical and Energy Engineering, Sapienza University of Rome, Italy. \\ ${ }^{3}$ Department of Planning, Design, and Technology of Architecture, Sapienza University of Rome, Italy.
}

\begin{abstract}
As envisaged in the 'Agenda for a sustainable and competitive European tourism', the adoption of a holistic and integrated approach and the use of the best available knowledge and technologies are key aspects to ensure sustainable tourism. In particular, policies and actions should be planned by considering the latest and best available knowledge, and, at the same time, analyzing all the related impacts on the area of intervention. In this context, this paper describes an approach to design sustainable tourist accommodations in areas characterized by high environmental value (e.g. natural protected areas) by minimizing the related impacts on the surrounding environment and sensitizing users towards preservation and conservation of natural resources. In fact, the aim of biodiversity conservation included in each rule for a natural protected area requires the application of eco friendly technologies and sustainable strategies for the protection of the natural heritage. In the proposed approach, three aspects of tourist accommodations have been considered: the system component, the building envelope and the integration between them. As a result, the architectural structures designed, including the materials, shape, energy efficiency, modularity and removability, are in line with the standards of bio-architecture. The materials used comply with the technical requirements and the technological needs of tourist accommodations, are mostly recycled or reusable and come from the surrounding area, so they can be easily integrated into the landscape. The components that make up the accommodations are easy to assemble and disassemble, making it possible for them to be reused in another area, without changing the environmental conditions at the new site. Some components are precast and prepared on-site using local materials whose modularity makes them highly suitable for use in different environmental and morphological conditions. To use these architectural structures in places without services and distribution networks for energy and water, special attention has been given to develop innovative and sustainable energy solutions: liquefied petroleum gas (LPG) has been used as the only energy vector, in combination with a cogeneration plant, to provide heat and electric energy as well as with specific building envelopes that allow the transfer of LPG into the walls to provide energy to innovative gas appliances. The environmental impact of the proposed approach was assessed by analyzing the environmental application of these structures in tourist accommodations in the Circeo National Park in Italy.

Keywords: Combined heat and power plant, environmental impact mitigation, innovative gas appliances, sustainable tourist accommodation.
\end{abstract}

\section{INTRODUCTION}

Competitiveness and sustainability of tourism are closely related because the quality of tourist destinations is mainly dependent on their natural and cultural environment and on their integration in a local community. The principles of sustainable tourism comprise environmental, economic and sociocultural dimensions and only if there is an appropriate balance between these three dimensions the long-term sustainability of tourism is guaranteed [1, 2]. Many scientific papers [3-8] have highlighted that tourism sustainability is based on several aspects: the responsible use of natural resources, the analysis of the environmental impact of the activities carried out, the exploitation of renewable energy sources, the conservation management of the surrounding natural and cultural heritage, and 
the local economic impact. The framework drawn up in 1996 [9], as a part of the comprehensive plan of action in Agenda 21, stated that tourism is a tool of strategic and economic importance, and that the benefits arising from the application of the principles of sustainable development to tourism include aspects that are of fundamental importance for the local community: a healthy and productive life in harmony with nature, contribution to the protection of the terrestrial ecosystem, shared decision making and planning of policies at the local level, the creation of jobs for local people and other similar aspects. In accordance with what is stated in the Italian government's report on tourism [10], sustainable tourism is expected to facilitate the following: optimization of the use of environmental resources for the development of tourism, thereby helping in the conservation of natural resources and biodiversity; appreciation of the sociocultural authenticity of host communities, thereby conserving their heritage and facilitating intercultural understanding and tolerance; implementation of economic transactions that are feasible in the long term, thereby distributing socioeconomic benefits to all stakeholders.

The recognition and management of tourism in and around protected areas is an essential tool for conservation. In fact, it supports the development and creates an awareness of several important values (ecological, cultural, spiritual, aesthetic, recreational and economic) that characterize the protected areas; moreover, it represents a useful means of generating income to ensure livelihood through activities aimed at the protection of biodiversity, ecosystem integrity and cultural heritage, as well as the improvement of the quality of life of local communities. Therefore, the high quality experiences that visitors can enjoy in protected areas will stimulate interest in the protection and preservation of assets that enrich these areas [11]. Nyaupane and Poudel [12] analyzed the relationships among biodiversity conservation, livelihood improvements and tourism development and showed that tourism helps the local population realize their aim of protection of biodiversity, reduces the dependence of people on natural resources and improves the livelihoods of people living around protected areas. Dharmaratne et al. [13] reported that in developing countries tourism could be a major source of income for governments to self-finance protected areas by the recovery of use and non-use values from tourists.

In the light of the above considerations, this paper proposes an integration of specific plant and building envelopes to plan new types of tourist accommodations that can minimize impacts on the surrounding environment and, at the same time, satisfy the tourism demand in natural protected areas. Therefore, the results of this research can be specifically applied to tourism building design in areas such as national parks or other types of natural protected areas, where the surrounding environment includes habitat and species protected by European or national directives. The main element of the plant system is a combined heat and power (CHP) system, which is particularly suitable for small-scale and micro-scale applications that hold great promise for the production of energy for buildings, as proposed by Alanne and Saari [14].

According to Alanne and Saari [14] and Hawkes and Leach [15], micro-scale and small-scale CHP systems are undergoing rapid development and are considered to be products with the most promising prospects for the near future.

\section{METHODS}

The methodology proposed in this paper aims to minimize the environmental impact of tourist accommodations in areas with high environmental value not connected to the electricity grid, and in the process maintain high levels of efficiency and comfort without leading to fragmentation of natural habitats $[16,17]$. The methodology describes the innovative component of the installed plant system and a sustainable design of the building envelope for the proposed tourist accommodation. 


\subsection{Analysis of the system components}

The planned system uses liquefied petroleum gas (LPG) as the sole energy source. The selected plant is a $6 \mathrm{kWe}$ CHP system that is used to generate heat and electricity for six tourist accommodations using pipes that are integrated into the landscape through building design. It will be possible to reduce the maximum electrical power consumption of each tourist accommodation to $1 \mathrm{~kW}$ by installing appliances that directly use LPG as fuel instead such as washing machines and refrigerators, which normally consume large amounts of electricity. Therefore, sockets that have been specifically designed for this purpose have been installed; these sockets have built-in power adapters for domestic gas appliances that are equipped with a connector that is compatible with the gas socket. Thus, it is possible to replace the electrical circuit required to generate the electromotive force with a similar extension of a gas-based 'plug and play' system, which is already present in the buildings for heating and for the kitchen, thereby limiting the use of electricity to the lighting system and to appliances with limited power consumption such as televisions and computers. In addition, the installation of a 'smart metering' system and an automated control for gas allows the efficient management of the energy systems. These control systems can be integrated with home automation programs, thereby enabling the management and control of all household appliances remotely using any portable device such as a smartphone, tablet or notebook.

\subsection{Analysis of the building envelope}

The external vertical wall of the tourist accommodations is composed of three layers. Moving from outside to inside it consists of a gabion wall (metal cages filled with local gravel), an air cavity through which gas pipes pass and wooden panels that are prefabricated and assembled on-site. All the external vertical walls are made of loose local material that is easy to assemble and disassemble, making it possible for them to be reused at other sites. The foundation, the roof and the interior walls are made of prefabricated panels that are assembled on-site. The structure is anchored to the foundation by means of L-shaped metallic brackets that ensure stability. The cavity between the existing wall and the coating structure is $7 \mathrm{~cm}$ thick. This thickness ensures enough ventilation to reduce the thermal load on the building via the chimney effect, which is caused by the ascending summer airflow through suitable openings provided for inlet and exhaust air that are located at the base and the top portions of the wall; these openings are covered by a metal grid to prevent the entry of animals and other materials.

Another method for producing the chimney effect is by the creation of breaches with metal grids on the panels at the ends of the wall. The space intended for the passage of pipes and valves of the gas system is designed in accordance with EU regulations, which require the availability of a ventilation system (Figure 1).

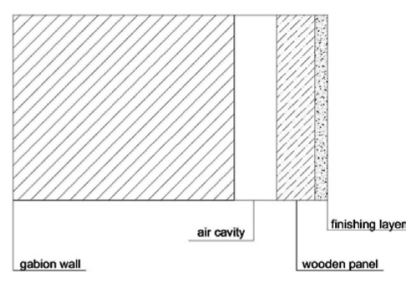

Figure 1: Section showing the layers that make up the external vertical wall. 


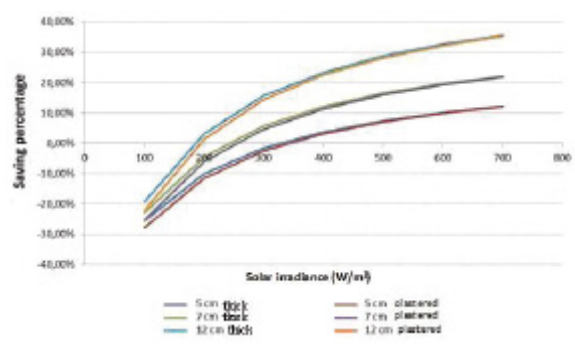

Figure 2: Percentage of energy saving for different values of solar irradiance and for different thicknesses of the ventilated wall.

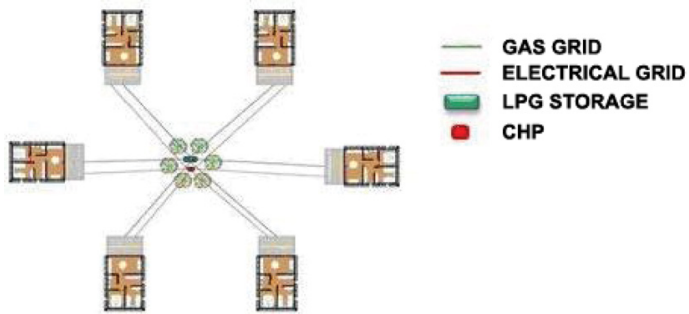

Figure 3: Electric and LPG supply for six tourist accommodations.

Figure 2 shows the effect of varying both the thickness of the ventilated cavity (from 5 to $12 \mathrm{~cm}$ ) and the thermal transmittance (from 1.1 to $0.3 \mathrm{~W} / \mathrm{m}^{2}$ ) of the package wall on which the ventilation panel is inserted. Based on these changes, the energy efficiency of the technological system was evaluated in terms of the saving rate relative to the reduction in the summer cooling load at different intensities of solar radiation incident on the wall and the outside temperature.

It is important to note that with increasing thickness of the gap and at high solar radiation, the transmittance value of the existing wall gradually loses its importance. Walls that are poorly insulated and have high cavity thickness are not very efficient under conditions of low solar radiation and high air temperatures.

\subsection{Integration of the system components with the casing}

The installation of a single $6 \mathrm{kWe}$ CHP plant for six tourist accommodation reduces the impacts on the environment and the landscape; in addition, since the thermal and electrical efficiency of the cogeneration unit depends on its power supply [18], it has higher thermal and electric efficiencies compared with six $1 \mathrm{kWe}$ CHP plants (Figure 3).

The pipes are integrated into the building envelope as they pass through the gap between the gabion wall and the internal wooden panel, which together constitute the external lateral walls.

\subsection{Environmental application of the integrated system component with the casing}

All the system components and the building envelope structures described in Sections 2.1-2.3 are designed to minimize the potential impacts on the surrounding environment. In fact, each construction can be easily disassembled, has no foundations and is made from local materials (prefabricated wood elements). 
Moreover, the proposed accommodations do not modify the local landscape where they are located as they are designed in the same colors as the surrounding environment and have dimensions that do not alter the profile of the landscape.

\section{RESULTS: FEASIBILITY OF THE INTEGRATED TECHNOLOGIES}

The smart metering system, which improves the grid efficiency through real-time control of all environmental and performance parameters of the system, allows significant savings, generally up to 5\% on electricity and heating consumption. Moreover, the use of a single energy carrier, combined with self-generation of electricity, allows savings resulting from favorable supply contracts with energy companies. Besides these achieved economic savings, the use of LPG for electricity production is less polluting compared with the electricity produced by traditional systems.

In particular, to assess the environmental impact of gas systems, a comparative life cycle analysis (LCA) was conducted on engines with a capacity below $5 \mathrm{~kW}$ fueled by gasoline, diesel, biodiesel, LPG, compressed natural gas $(\mathrm{CNG})$ and electric batteries using three different types of electric power production for supply: the first is the European and North American standard (AvBEV), the second does not include nuclear energy as in the case of Italy (EvnoNU), and the last includes electric energy produced entirely from renewable sources such as solar, wind and hydroelectric power (EVR). To obtain an immediately understandable overall assessment of the impact on air quality impact at a local and global scale caused by each equipment, eco-points resulting from the LCA analysis, after taking into account the air pollutants and the total production of greenhouse gases, were calculated (ISO 14040, 14042 Standards and ECO_INDICATOR 99 methodology) [19, 20]. By combining these eco-points, it is possible to normalize the overall impacts based on evaluation bands, ranging from a negligible to a critical level, obtained for increasing values of the eco-points of the individual impacts (Figure 4).

The analysis of the results of the environmental impacts arising from various types of plants, using comparative LCA, shows how LPG and CNG offer significant benefits in terms of greenhouse gas (GHG) emissions (reduction of 18\%) and air quality (reduction of 19\%), compared with oil and diesel fuel power plants. Technologies based on LPG and CNG have a lesser impact on electric motors powered by the Italian energy mix. In Europe and North America, the technologies are equivalent as LPG and CNG have a better performance when considering air pollutant emissions than electric motors, even though they produce larger quantities of GHGs, which in any case results in environmental impacts that are broadly equivalent. Only in the case of complete electrical energy production from

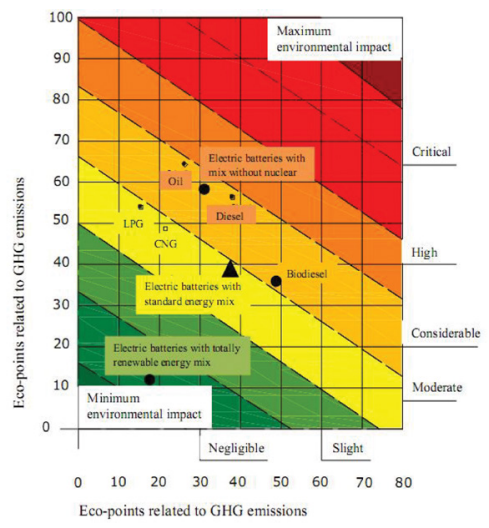

Figure 4: Environmental impacts of different types of energy supplies calculated using LCA analysis. 
renewable sources, the electric technology is more sustainable, as, in spite of an equivalent emission of air pollutants, GHG emissions are reduced to almost zero [21]. However, it should be emphasized that in the current scenario such a solution would entail unrealistic costs for large-scale application. To assess the cost of installing a gas cogeneration system for residential use, a comparison was performed, in terms of the energy and cost savings, between a traditional system (boiler and connection to the grid) and an innovative solution that consists of a gas CHP system (Figure 5). The method of calculation takes into account the variability of the climate, the degree days and the configuration of the building, in terms of the ratio of the dispersion surface to the heated volume $(\mathrm{S} / \mathrm{V})$. The conversion factors have been fixed based on the values currently defined by the Italian regulations.

The curves in Figure 5 show that the primary energy saving, which is the sum of the primary energy taken from the public grid for heating and the production of electricity, increases proportionally with the degree day at the study location. On analyzing the results, it is evident that the performance is enhanced in colder regions, where there is a need for larger amounts of heat to be produced using the co-generator, which also increases the electrical energy produced by CHP. Therefore, as the residential electricity needs are almost constant with respect to the degree days, the amount of electricity drawn from the grid decreases progressively with an increase in the degree days, resulting in a primary energy saving. A major primary energy and economic saving is obtained in cases where the $\mathrm{S} / \mathrm{V}$ ratio is higher. In fact, buildings with high $\mathrm{S} / \mathrm{V}$ values are characterized by greater heat consumption due to the increased dispersion surface; consequently, in this case the increased use of CHP for heating also leads to a higher production of electricity and, as in the previous case, a reduction in the amount of electricity drawn from the grid. All this leads to a reduction in the primary energy consumption of the building.

\subsection{The Circeo National Park case study}

The methodology described in Section 2 has been applied as a case study in the design of tourist accommodations in the Circeo National Park in Italy, to assess the environmental impact of the designed facility (Figure 6).

All factors that have been taken into account in the design of the tourist accommodation are related to the reduction in the environmental impact of the planned structure. Prefabricated panels assembled on-site have been used to build the walls of the buildings. Moreover, the use of recycled or reusable local materials has been encouraged to improve the integration of the building into the landscape and reduce transportation costs. The external walls of the tourist accommodations are filled with local material, in particular lapillus. The choice of this material has been justified because it is readily available in Italy, in the numerous quarries spread throughout the country, and because of its high thermal and acoustic insulation coefficients, high porosity and its resistance to fire. With regard to landscaping impacts, all colors of the architectural elements have been chosen to facilitate the integration of these buildings into the surrounding environment.

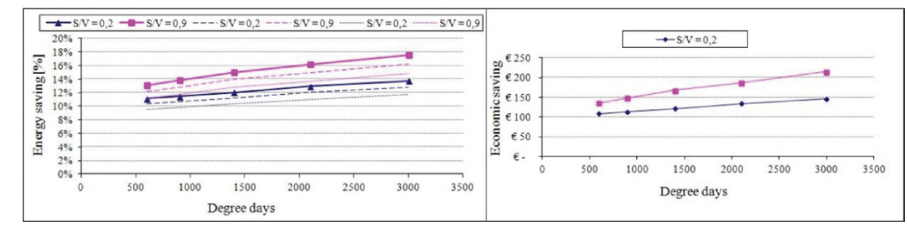

Figure 5: Energy and economic saving resulting from the use of a CHP plant compared with the traditional solution for a floor area of $100 \mathrm{~m}^{2}$ with an energy requirement of $\leq 30 \mathrm{kWh} / \mathrm{m}^{2}$ per year. 


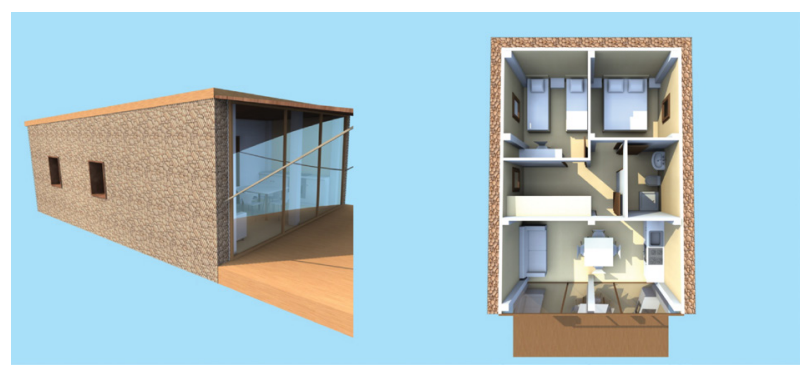

Figure 6: Lateral and planimetric views of the designed facility.

Environmental impacts were also reduced using a system of physical elements (modules) that allow the realization of a flexible construction system capable of generating multiple shapes that can be modified based on the varying space requirements. The designed plant system is described in Section 2. The pipes located on the outside of the buildings can be laid on the ground and covered with bumps that are similar in color to the surrounding ground, to minimize the environmental impact. Such a provision does not require excavation and allows easier access to the system for removal or repair. Thus, the adopted system, which uses the cavities between the gabion wall and the internal wooden panel for the passage of gas pipes, may be an example of integration of an element plant with an architectural element to simultaneously improve the insulation of external enclosures by avoiding thermal bridges and internal humidity resulting from surface and interstitial condensation.

\section{DISCUSSION AND CONCLUSIONS}

The proposed approach shows that it is possible to integrate the development of ecotourism with the principle of sustainability by balancing and integrating the natural and built environments with the design process, the technology used and the management of a tourist accommodation.

The approach presented in this paper describes the integration of tourist accommodations that are designed in compliance with the environmental restrictions present in protected areas where they are located. The architectural design of the proposed buildings is closely linked to plant engineering and the choice of materials to allow the integration of the buildings into the protected environment. The proposed tourist accommodations are mainly based on the principles of modularity and removability; they consist of modular blocks of living space that do not require excavation, are equipped with all the necessary amenities and are reachable by specially made foot and bicycle paths. Moreover, the modularity of the living spaces allows the creation of solutions adapted to various morphological and environmental conditions. The materials used are locally available, can be recycled or reused and meet the technical requirements needed for their final use.

Furthermore, the presence of these sustainable tourist accommodations in areas of high environmental value offers visitors the possibility to sensitize their awareness on environmental issues, thereby helping citizens to get involved in nature conservation activities.

To allow the realization of these tourist accommodations in areas of high environmental value not connected to the electricity grid, specific attention has been given to the choice of an energy solution that can meet the local and specific needs and, at the same time, is innovative and sustainable. LPG combined with cogeneration has been used to develop energy self-sufficient structures.

Sustainability in construction is an essential requirement by the current regulations, but in practice it is not always enforced owing to the lack of a specific culture in the construction industry. In recent years, the process of constructing a building has become increasingly complex as a result of additional requirements to be met, one of which is its sustainability and the achievement of the degree of satisfaction of the end-users in terms quality of the building product. 
In building systems, the application of sustainability issues is limited by several constraints and difficulties. Unfortunately, in the construction industry, there is a tendency not to deal with the problems in terms of the overall cost/benefit, including the environment, but to limit the objectives to the optimization of only the economic aspects of a real estate project, leaving the further commitment of monitoring and verifying of other costs, environmental and energy, to the community.

During the last few years, all the stakeholders involved in the construction industry have concentrated their efforts on ecotourism. But the loss of biodiversity and habitats still exist as well as the uncontrolled construction of infrastructure and unsustainable land use, often caused by improper planning, design and management of tourism development and tourist accommodation.

The transferability of the presented approach to other contexts is one of the fundamental aims of the research: to support public administrations, private enterprises and any initiative that aims to inform tourists and inhabitants of the towns affected by the proposed constructions on issues that cannot always be understood easily and immediately, so as to transfer and share the choices made. In this way, the research is open to civil society as it identifies the problems and proposes solutions by taking into account the overall cost/benefit ratio, in both economic and social terms.

The methodology and framework presented can be developed further in this and other areas of research; one of the areas of the proposed approach that needs further development is interdisciplinarity, which integrates specific areas of expertise with others from different disciplines, forming an entire framework for spatial planning, transferability and the dissemination of the topics examined to the community.

A starting point for future developments of the proposed approach could be the introduction of a system of combined heat and residential energy (CHP) powered by hydrogen. In fact, the use of hydrogen technology - an energy carrier that can be produced using a variety of primary energy sources and production technologies - could be a good long-term solution that makes an important contribution to sustainable development [22-24].

\section{REFERENCES}

[1] Janusz, G.K. \& Bajdor, P., Towards to sustainable tourism - framework, activities and dimensions. Procedia Economics and Finance, 6, pp. 523-529, 2013. doi: http://dx.doi.org/10.1016/ $\underline{\mathrm{s} 2212-5671(13) 00170-6}$

[2] Andersson, T.D. \& Lundberg, E., Commensurability and sustainability: triple impact assessments of a tourism event. Tourism Management, 37, pp. 99-109, 2013. doi: http://dx.doi. org/10.1016/j.tourman.2012.12.015

[3] Astiaso Garcia, D., Cumo, F., Sforzini V., \& Albo, A., Eco friendly service buildings for sustainable tourism and environmental awareness in protected areas. WIT Transactions on Ecology and the Environment, 161, pp. 323-330, 2012. doi: http://dx.doi.org/10.2495/st120261

[4] Cinquepalmi, F., Cumo, F., Gugliermetti, F. \& Sforzini, V. Advanced technologies for sustainable building in the protected areas: two case studies in Italy. WIT Transactions on Ecology and the Environment, 128, pp. 551-560, 2010. doi: http://dx.doi.org/10.2495/arc100471

[5] Cumo, F., Cinquepalmi, F., Pennacchia, E. \& Sforzini, V. High performing building as a pier for sustainable tourism in the protected area of Bracciano Lake in Italy. WIT Transactions on Ecology and the Environment, 165, pp. 175-182, 2012. doi: http://dx.doi.org/10.2495/arc120161

[6] Ko, T.G., Development of a tourism sustainability assessment procedure: a conceptual approach. Tourism Management, 26(3), pp. 431-445, 2005. doi: http://dx.doi.org/10.1016/j. tourman.2003.12.003

[7] Choi, H.C. \& Sirakaya, E., Sustainability indicators for managing community tourism. Tourism Management, 27(6), pp. 1274-1289, 2006. doi: http://dx.doi.org/10.1016/j.tour$\underline{\operatorname{man} .2005 .05 .018}$ 
[8] Lozano-Oyolaa, M., Blancas, F.J., González, M. \& Caballero, R., Sustainable tourism indicators as planning tools in cultural destinations. Ecological Indicators, 18, pp. 659-675, 2012. doi: http://dx.doi.org/10.1016/j.ecolind.2012.01.014

[9] World Tourism Organization, World Travel and Trade Council, Earth Council, Agenda 21 for the Travel and Tourism Industry, 1996. doi: http://dx.doi.org/10.1177/004728759403200388

[10] Osservatorio Nazionale del Turismo, Istat, Banca d'Italia, Unioncamere-Isnart, Rapporto Turismo 2012, Presidenza del Consiglio dei Ministri, 2013.

[11] Bushell, R. \& Eagles, P.F.J. (eds), Tourism and Protected Areas: Benefits Beyond Boundaries (The Vth IUCN World Park Congress), CABI: Oxfordshire, 2007. doi: http://dx.doi. org/10.1079/9780851990224.0000

[12] Nyaupane, G.P. \& Poudel, S., Linkages among biodiversity, livelihood, and tourism. Annals of Tourism Research, 38(4), pp. 1344-1366, 2011.

[13] Dharmaratne, G.S., Sang, F.Y. \& Walling, L.J., Tourism potentials for financing protected areas. Annals of Tourism Research, 27(3), pp. 590-610, 2000. doi: http://dx.doi.org/10.1016/ $\underline{\mathrm{s} 0160-7383(99) 00109-7}$

[14] Alanne, K. \& Saari, A., Sustainable small-scale CHP technologies for buildings: the basis for multi-perspective decision-making. Renewable and Sustainable Energy Reviews, 8, pp. 4001-4031, 2004. doi: http://dx.doi.org/10.1016/j.rser.2003.12.005

[15] Hawkes, A.D. \& Leach, M.A., Cost-effective operating strategy for residential micro-combined heat and power. Energy, 32, pp. 711-723, 2007. doi: http://dx.doi.org/10.1016/j.energy.2006.06.001

[16] Astiaso Garcia, D., Bruschi, D., Cinquepalmi, F. \& Cumo, F., An estimation of urban fragmentation of natural habitats: case studies of the 24 Italian national parks. Chemical Engineering Transactions (ICheaP-11, 11th International Conference on Chemical \& Process Engineering), 32, pp. 49-54, 2013.

[17] De Santoli, L., Astiaso Garcia, D. \& Violante, A.C., Planning of flood defence management and rehabilitation of the natural habitat in the downstream part of the river Tiber. WIT Transaction on the Built Environment, 100. pp. 25-34, 2008. doi: http://dx.doi.org/10.2495/geo080031

[18] Bianchi, M., De Pascale, A. \& Spina, P.R., Guidelines for residential micro-CHP systems design. Applied Energy, 97, pp. 673-685, 2012. doi: http://dx.doi.org/10.1016/j.apenergy.2011.11.023

[19] Audenaert, A., De Cleyn, S.H. \& Buyle, M., LCA of low-energy flats using the Eco-indicator 99 method: impact of insulation materials. Energy and Buildings, 47, pp. 68-73, 2012. doi: http://dx.doi.org/10.1016/j.enbuild.2011.11.028

[20] Astiaso Garcia, D., Cinquepalmi, F. \& Cumo, F., Air quality in Italian small harbours: a proposed assessment methodology. Rendiconti Lincei, 24(4), pp. 309-318, 2013. doi: http:// dx.doi.org/10.1007/s12210-013-0254-0

[21] Cumo, F., Astiaso Garcia, D., Calcagnini, L., Rosa, F. \& Sferra, A.S., Urban policies and sustainable energy management. Sustainable Cities and Society, 4, pp. 29-34, 2012. doi: http:// dx.doi.org/10.1016/j.scs.2012.03.003

[22] De Santoli, L., Lo Basso, G. \& Bruschi, D., Hybrid system with an integrated CHP plant fuelled by $\mathrm{H}_{2} \mathrm{NG}$ blends: theoretical energy-environmental analysis and foreseeable optimizations. Energy and Building, 71, pp. 88-94, 2014. doi: http://dx.doi.org/10.1016/j.enbuild.2013.12.008

[23] De Santoli, L., Lo Basso, G. \& Bruschi, D. Energy characterization of CHP (combined heat and power) fuelled with hydrogen enriched natural gas blends. Energy, 60, pp. 13-22, 2013. doi: http://dx.doi.org/10.1016/j.energy.2013.07.012

[24] De Santoli, L., Lo Basso, G. \& Bruschi, D., A small scale $\mathrm{H}_{2} \mathrm{NG}$ production plant in Italy: techno-economic feasibility analysis and costs associated with carbon avoidance. International Journal of Hydrogen Energy, 39(12), pp. 6497-6517, 2014. doi: http://dx.doi.org/10.1016/j. ijhydene.2014.02.003 